\title{
POSSÍVEIS EXPLICAÇÕES PARA A SEMELHANÇA ENTRE AS REFORMAS EDUCACIONAIS ATUAIS E AS PROPOSTAS NA ÉPOCA DA DITADURA CIVIL- MILITAR NO BRASIL
}

\author{
Gabriela Ribeiro de Campos $^{1}$ \\ Maria de Lourdes Gisi ${ }^{2}$
}

\section{INTRODUÇÃO}

Os debates sobre a necessidade de uma reforma do ensino médio não são de hoje no Brasil e a definição de políticas para esta etapa da educação básica tem sido controvertida, como assinala Krawczyk (2011, p. 755): “fala-se da perda da identidade, quando na verdade o ensino médio nunca teve uma identidade muito clara, que não fosse o trampolim para a universidade ou a formação profissional".

Esta dificuldade em definir uma identidade para o ensino médio tem relação com as disputas entre diferentes projetos sociais "que concorrem pela apropriação de parcela do conhecimento socialmente produzido, e entre distintos grupos profissionais pelo seu potencial de ampliação da inserção no mercado de trabalho" (KRAWCZYK, 2011, p. 757).

Por isso, a educação é estratégica e indispensável para a consolidação de qualquer projeto de nação e as ações tomadas nesse campo por meio de políticas públicas deixam claro quais concepções de mundo estão sendo priorizadas em cada governo, assim como expõem as disputas de classes sociais que estão em jogo. Sendo assim, parece que quanto mais as ideologias dos governos se aproximam, mais seus programas educacionais apresentam pontos em comum.

Após acompanhar o processo de formulação e aprovação da reforma do Ensino Médio e da Base Nacional Comum Curricular (BNCC) entre 2013 e 2018, em um cenário político conturbado no Brasil, é notável a semelhança das Leis $\mathrm{n}^{\circ} 12.796 / 2013$ e $\mathrm{n}^{\circ} 13.415 / 2017$, que legitimaram tais mudanças na Lei de Diretrizes e Bases da Educação Nacional vigente (LDB n 9.394/96), com a Lei $\mathrm{n}^{\circ}$ 5.692/71, período da Ditadura Civil-Militar no país.

\footnotetext{
1 Doutoranda do Programa de Pós-Graduação em Educação da PUC-PR. ORCID: <https://orcid.org/0000-00025796-3639>. E-mail: gabriela.campos3@gmail.com.

${ }^{2}$ Professora Titular do Programa de Pós-Graduação em Educação da PUCPR. ORCID: <https://orcid.org/0000-0002-0474-474X>. Email: maria.gisi@pucpr.br.
} 
Nessa direção, pretendo mostrar neste artigo as semelhanças entre essas três leis, de épocas distintas e separadas por mais de 30 anos no tempo. Busco ainda apontar possíveis explicações para a proximidade desses projetos educacionais para o Ensino Médio e para a educação brasileira, mesmo que eles estejam situados em diferentes momentos históricos.

\section{A REFORMA DO ENSINO MÉDIO E A BASE NACIONAL COMUM CURRICULAR: BREVE HISTÓRICO}

Em 2013, a Comissão Especial para Reformulação do Ensino Médio (CEENSI) criada na época, cujo presidente era o então deputado federal Reginaldo Lopes, propôs um Projeto de Lei (P.L. 6.840) que visava modificar a LDB nº 9.394/96 neste nível de ensino.

A principal alteração proposta pelo projeto foi a reorganização do currículo do ensino médio, que passaria a ser estruturado nas seguintes áreas do conhecimento: linguagens, matemática, ciências da natureza e ciências humanas. Dentro desse novo modelo, o aluno do terceiro ano poderia escolher pela formação que mais se adequasse às suas preferências e necessidades. Nessa direção, deveriam ser priorizadas a interdisciplinaridade, a transversalidade e a maior interação entre os diferentes componentes e conteúdos curriculares (BRASIL, 2013a).

Para isso, de acordo com o documento, os currículos do ensino médio deveriam seguir uma base nacional comum e priorizar o ensino:

[...] da língua portuguesa, da matemática, o estudo do mundo real físico e natural, da realidade social e política, especialmente a brasileira, e de uma língua estrangeira aplicada à opção formativa e/ou habilitação profissional do aluno, além daquela já adotada na parte diversificada do currículo (BRASIL, 2013a).

Deveriam fazer parte dessa base comum: a) conhecimentos sobre ciências, artes, letras e transformações sociais e culturais; e, b) temas considerados de grande relevância para os jovens e fundamentais para seu crescimento pessoal e cidadão, como: uso de drogas e álcool, meio ambiente, educação sexual, noções básicas da Constituição Federal, do Código de Defesa do Consumidor, importância do exercício da cidadania, participação política, democracia e ética na política (BRASIL, 2013a).

A segunda alteração mais relevante propunha a adoção da jornada em tempo integral no ensino médio. A carga horária passaria de 2.400 horas para 4.200 horas, ou seja, no mínimo sete horas de aula por dia. O Projeto de Lei entendia ser indispensável ampliar a permanência do aluno 
na escola para que eles fossem capazes de desenvolver adequadamente suas possibilidades formativas (BRASIL, 2013a).

Todas as iniciativas propostas na legislação em questão foram, segundo o próprio documento, resultado dos trabalhos realizados pela Comissão Especial destinada a promover Estudos e Proposições para a Reformulação do Ensino Médio (CEENSI):

Durante os mais de dezessete meses de funcionamento da Comissão Especial, foram realizadas dezenas de Audiências Públicas, Seminários Estaduais e um Seminário Nacional nos quais foram debatidas as razões para a falta de interesse dos jovens no ensino médio e para os resultados pouco promissores obtidos neste nível de ensino (BRASIL, 2013a).

Em agosto de 2016, mês em que Dilma Roussef foi deposta e Michel Temer assumiu interinamente a Presidência da República, os trâmites do P.L. 6.840 estacionaram. No final de setembro, o governo federal encaminhou a Medida Provisória $\mathrm{n}^{\mathrm{o}} 746$ - que propunha a reestruturação do Ensino Médio - ao Congresso Nacional (BRASIL, 2016a). Os meses seguintes foram marcados pela ocupação de escolas secundaristas e universidades públicas pelos alunos, como forma de manifestação contrária às PEC 746 e 241, e por protestos de todos aqueles que eram avessos a tais medidas.

Mesmo com a baixíssima aceitação popular, a medida provisória foi aprovada pela Câmara dos Deputados em dezembro de 2016. No dia 08 de fevereiro de 2017, foi aprovada no Senado e no dia 16 do mesmo mês foi sancionada pelo então Presidente da República, Michel Temer, resultando na Lei $n^{\circ}$ 13.415. Paralelamente à reforma do Ensino Médio, caminhava a formulação da chamada Base Nacional Comum Curricular.

A demanda por uma base nacional comum não é nova na educação. Em 1949, o Ministério da Educação e da Cultura (MEC) já havia tomado a primeira iniciativa na direção de estabelecer bases gerais para o ensino (GONTIJO, 2015), com o propósito de organizar o sistema curricular para os programas das disciplinas dos cursos primários.

Em 11 de agosto de 1971 foi promulgada a Lei $n^{\circ}$ 5.692, que fixava as diretrizes e bases para o ensino de $1^{\circ}$ e $2^{\circ}$ graus. O documento sustentou a reforma desses níveis de ensino no período da Ditadura Civil-Militar no Brasil, que precisavam estar alinhados às mudanças realizadas no ensino superior e, mais especificamente, ao projeto de educação nacional e internacional para o país, nos moldes capitalistas. 
Na mesma direção, a Constituição Federal de 1988 afirma no artigo 210 que "serão fixados conteúdos mínimos para o ensino fundamental, de maneira a assegurar formação básica comum e respeito aos valores culturais e artísticos, nacionais e regionais" (BRASIL, 1988). A LDB 9.394, de 1996, aponta no artigo 9, inciso IV, que caberá à União:

[...] estabelecer, em colaboração com os Estados, o Distrito Federal e os Municípios, competências e diretrizes para a educação infantil, o ensino fundamental e o ensino médio, que nortearão os currículos e seus conteúdos mínimos, de modo a assegurar formação básica comum (BRASIL, 1996).

Mais recentemente, as Diretrizes Curriculares Nacionais (DCNs) reuniram as novas orientações para a educação básica brasileira ${ }^{3}$ (BRASIL, 2013b). O Plano Nacional de Educação para o período de 2014 a 2024, por sua vez, prevê nas estratégias 2.2. e 3.3 o pacto entre União, estados, Distrito Federal e municípios para a implantação dos direitos e objetivos de aprendizagem e desenvolvimento que configurarão a base nacional comum curricular do ensino fundamental e ensino médio (BRASIL, 2014).

Com efeito, ela começa a ser formulada no primeiro semestre de 2015. Em seu processo de produção e organização, reuniu membros de associações científicas representativas das diversas áreas do conhecimento de universidades públicas, o Conselho Nacional dos Secretários de Educação (Consed), a União Nacional dos Dirigentes Municipais da Educação (Undime) e, em especial, representantes dos aparelhos privados de hegemonia da classe empresarial, como Movimento Todos pela Educação (2006), Fundação Leman (2002), Movimento pela Base Nacional Comum Curricular (2013), entre outros. Tratam-se de organizações que desejam guiar as políticas educacionais dentro de uma lógica mercantil (TRICHES \& ARANDA, 2016).

No dia 16 de setembro de 2015 foi lançada a primeira proposta da BNCC, já durante o governo interino assumido pelo vice-presidente Michel Temer. Entre setembro do mesmo ano e março de 2016, o Conselho Nacional da Educação (CNE) promoveu o período de consulta pública ao documento e no dia 03 de maio de 2016, o Ministério da Educação (MEC) lançou a segunda versão da BNCC.

No dia 6 de abril de 2017, uma terceira versão da base foi entregue pelo MEC ao CNE. Entre junho e setembro do mesmo ano, o CNE realizou audiências públicas regionais em Manaus,

\footnotetext{
${ }^{3}$ As DCNs continuam valendo, como fica claro na versão completa em revisão do documento referente às alterações na etapa do Ensino Médio, aprovada pelo CNE em 04 de dezembro de 2018. O documento cita as DCNs várias vezes, reforçando sua vigência e sua compatibilidade com a BNCC (BRASIL, 2018).
} 
Recife, Florianópolis, São Paulo e Brasília, com caráter exclusivamente consultivo, destinadas a colher subsídios e contribuições para a elaboração da norma instituidora da Base Nacional Comum Curricular. Estas audiências não tiveram caráter deliberativo e resultaram em 235 documentos protocolados com contribuições recebidas no âmbito das audiências públicas, além de 283 manifestações orais (BRASIL, 2017b).

No dia 15 de dezembro, o parecer e o projeto de resolução apresentados pelos conselheiros relatores do CNE foram votados em Sessão do Conselho Pleno e aprovados com 20 votos a favor e 3 contrários. Após esse resultado, no dia 20 de dezembro de 2017, as etapas da Educação Infantil e do Ensino Fundamental foram homologadas pelo então Ministro da Educação, Mendonça Filho, e dois dias depois foi publicada a Resolução $\mathrm{CNE} / \mathrm{CP} \mathrm{n}^{\circ}$ 2, que instituiu e orientou a implantação da Base Nacional Comum Curricular nesses dois níveis educacionais. Em 3 de abril de 2018, o MEC entregou ao CNE uma nova versão da Base para o Ensino Médio, que foi aprovada no dia 05 de dezembro ${ }^{4}$.

Nessa direção, as leis que modificaram a LDB 9.394/96, legitimando a Reforma do Ensino Médio e instituindo a BNCC na principal legislação da educação brasileira foram a Lei nำ12.796, de 4 de abril de 2013 e, principalmente, a Lei $n^{\circ}$ 13.415, de 4 de abril de 2017. Ambas apresentam semelhanças significativas com a Lei $n^{\circ}$ 5.692/71, que fixou Diretrizes e Bases para o ensino de $1^{\circ}$ e $2^{\circ}$ graus e deu outras providências à educação no período da Ditadura Civil-Militar no Brasil. Vejamos essas analogias para depois tentar compreender possíveis motivos para tal proximidade.

\section{SEMELHANÇAS ENTRE AS LEIS No 5.692/71, N 12.796/2013 E No 13.415/2017}

Começando pela Lei $\mathrm{n}^{\circ} 12.796$, de 4 de abril de 2013, ela altera o artigo 26 da LDB 9.394/96 e estabelece que:

Art. 26. Os currículos da educação infantil, do ensino fundamental e do ensino médio devem ter base nacional comum, a ser complementada, em cada sistema de ensino e em cada estabelecimento escolar, por uma parte diversificada, exigida pelas características regionais e locais da sociedade, da cultura, da economia e dos educandos (BRASIL, 2013c).

De maneira muito parecida, o artigo $4^{\circ}$ da Lei $n^{\circ} 5.692 / 71$ garante que:

\footnotetext{
${ }^{4}$ Essas informações foram retiradas do site oficial do Ministério da Educação (MEC).
} 
Art. $4^{\circ}$ Os currículos do ensino de $1^{\circ}$ e $2^{\circ}$ graus terão um núcleo comum, obrigatório em âmbito nacional, e uma parte diversificada para atender, conforme as necessidades e possibilidades concretas, às peculiaridades locais, aos planos dos estabelecimentos e às diferenças individuais dos alunos (BRASIL, 1971).

Ambos afirmam que os currículos da educação básica devem ter uma base comum de conhecimentos. Esse núcleo básico deve ser complementado por uma parte diversificada que atenda, segundo as leis, diferenças entre os alunos, assim como diferenças locais, regionais, culturais, etc. A proximidade dos dois textos é nítida, principalmente no que diz respeito aos seus significados, aquilo que desejam colocar em prática.

Dando sequência à análise, a Lei no 5.692/71 imputava ao Conselho Federal de Educação a definição dos conteúdos escolares e das matérias relativas a um núcleo comum, seus objetivos e sua amplitude para cada grau. Os Conselhos de Educação deviam relacionar as disciplinas dentre as quais os estabelecimentos de ensino podiam escolher para constituir a parte diversificada de seus currículos.

As escolas podiam ofertar ainda estudos que não estavam nessa lista, mas mediante a aprovação dos respectivos Conselhos de Educação. No que diz respeito ao ensino de $2^{\circ}$ grau, o Conselho Federal de Educação era o responsável por fixar o núcleo comum e o mínimo a ser exigido em cada habilitação profissional ou conjunto de habilitações afins. Cabia também ao órgão aprovar ou não outras habilitações profissionais oferecidas pelos estabelecimentos de ensino que não correspondiam às já previstas.

De forma parecida, a Lei $\mathrm{n}^{\circ}$ 13.415/2017 indica que cabe ao Conselho Nacional de Educação (CNE) apontar os direitos e objetivos de aprendizagem definidos pela BNCC no Ensino Médio. Os sistemas de ensino podem incluir projetos e pesquisas envolvendo os temas transversais especificados na LDB Lei $n^{\circ}$ 9.394/96, mas cabe ao CNE aprovar ou não a inclusão de novos componentes curriculares de caráter obrigatório na BNCC.

Além disso, a Lei $\mathrm{n}^{\circ}$ 5.692/71 determinava que, asseguradas as normas de cada sistema de ensino, o currículo pleno teria uma parte de educação geral e outra de formação especial. A formação geral era exatamente esse conjunto de conhecimentos que deveriam ser a base da educação nacional, ministrada a todos os brasileiros, garantindo-lhes o mínimo de instrução para ingressar no mercado de trabalho. A formação especial abrigava os saberes técnicos e profissionais 
transmitidos principalmente no $2^{\circ}$ grau, voltados para aqueles que concluiriam os estudos e/ou seguiriam para o ensino superior.

Essa estrutura estava organizada da seguinte maneira pela lei:

Art. $5^{\circ}, \S 1^{\circ}$

a) no ensino de primeiro grau, a parte de educação geral seja exclusiva nas séries iniciais e predominantes nas finais;

b) no ensino de segundo grau, predomine a parte de formação especial;

$\S 2^{\circ}$ A parte de formação especial de currículo:

a) terá o objetivo de sondagem de aptidões e iniciação para o trabalho, no en sino de $1^{\circ}$ grau, e de habilitação profissional, no ensino de $2^{\circ}$ grau;

b) será fixada, quando se destina a iniciação e habilitação profissional, em consonância com as necessidades do mercado de trabalho local ou regional, à vista de levantamentos periodicamente renovados

$\S 3^{\circ}$ Excepcionalmente, a parte especial do currículo poderá assumir, no ensino de $2^{\circ}$ grau, o caráter de aprofundamento em determinada ordem de estudos gerais, para atender a aptidão específica do estudante, por indicação de professores (sic) e orientadores (BRASIL, 1971).

Em seu artigo $8^{\circ}$ constava ainda que o currículo devia ser ordenado por séries anuais ou semestrais de disciplinas ou áreas de estudos, organizadas conforme o plano e as possibilidades do estabelecimento, ou visando atender as diferenças individuais dos alunos. No ensino de $2^{\circ}$ grau, devia ser ofertada uma variedade de habilitações e era possível a matrícula por disciplinas sob condições que assegurassem o relacionamento, a ordenação e a sequência dos estudos.

De acordo com o Parecer $n^{\circ} 853 / 71$, analisado por Romanelli (1978, p. 242), o núcleo comum comportava as matérias fixadas pelo Conselho Federal de Educação e era considerado a educação mínima de qualquer cidadão. Segundo o parecer, a escolha dessas disciplinas buscou situá-las dentro da perspectiva de "todo o conhecimento humano", mas afirmou que era possível chegar ao destaque de partes, de grandes linhas, sem retirá-las funcionalmente do seu todo natural. Assim, o documento propõe a seguinte classificação: a) comunicação e expressão; b) estudos sociais, e c) ciências.

Dentro da mesma concepção, a Lei n ${ }^{\circ}$ 13.415/2017 define que os conteúdos previstos na BNCC se dividirão nas seguintes áreas do conhecimento: I) linguagens e suas tecnologias; II) 
matemática e suas tecnologias; III) ciências da natureza e suas tecnologias; e, IV) ciências humanas e sociais aplicadas. $\mathrm{O}$ documento deixa claro que a parte diversificada dos currículos (definidas em cada sistema de ensino, como visto há pouco), deve estar harmonizada com a BNCC e articulada com o contexto histórico, econômico, social e cultural.

Especificamente no ensino médio, o currículo também deve ser organizado conforme a BNCC, mas no formato de itinerários formativos. Esses itinerários nada mais são do que a oferta de diferentes arranjos curriculares, conforme a relevância para o contexto local e as possibilidades dos sistemas de ensino, segundo a legislação. Eles seguem as mesmas quatro áreas do conhecimento mencionadas acima, mais a formação técnica e profissional. Conforme a lei, os alunos concluintes do ensino médio que quiserem podem cursar mais de um itinerário formativo mediante disponibilidade de vagas na rede de ensino.

Na Lei $n^{\circ} 5.692 / 71$, o artigo $7^{\circ}$ aditava a obrigatoriedade das disciplinas de Educação Moral e Cívica, Educação Física, Educação Artística e Programas de Saúde nos currículos plenos dos estabelecimentos de $1^{\circ}$ e $2^{\circ}$ graus. $O$ ensino religioso, alvo de debates constantes nas políticas educacionais, mesmo que de matrícula facultativa, devia se tornar disciplina dos horários normais das escolas. $\mathrm{O}$ artigo $10^{\circ}$ instituía obrigatoriamente a Orientação Educacional, incluindo aconselhamento vocacional, em cooperação com os professores, a família e a comunidade. A língua nacional deveria ser priorizada por ser instrumento indispensável de comunicação e de expressão da cultura brasileira.

$\mathrm{Na}$ LDB - Lei ${ }^{\circ} 9.394 / 96$, por sua vez, as alterações da Lei 13.415/17, estabelece que a "Base Nacional Comum Curricular referente ao ensino médio incluirá obrigatoriamente estudos e práticas de educação física, arte, sociologia e filosofia" (BRASIL, 2017a) e reforça a obrigatoriedade do ensino da língua portuguesa e da matemática nos três anos do ensino médio. No que diz respeito à língua estrangeira, define que os currículos do ensino médio devem incluir obrigatoriamente o ensino do inglês e demais línguas estrangeiras podem ser ofertadas em caráter optativo, preferencialmente o espanhol.

Tanto a Lei $n^{\circ}$ 5.692/71 quanto a Lei $n^{\circ} 13.415 / 2017$, dão grande importância à educação técnica e profissional voltada para o mercado de trabalho. Com esse intuito, abrem precedentes para as parcerias, inclusive as público-privadas. A primeira afirma no artigo $3^{\circ}$ que os sistemas de ensino devem estimular a oferta de modalidades diferentes de estudos integrados por meio da reunião de pequenos estabelecimentos em unidades mais amplas; da entrosagem e intercomplementariedade dos estabelecimentos de ensino; entre si ou com outras instituições sociais e da organização de 
centros interescolares que reúnam serviços e disciplinas ou áreas de estudo comuns a vários estabelecimentos (BRASIL, 1971).

A segunda estimula a oferta de cursos técnicos ofertados pela própria instituição ou em parceria com outras e garante a certificação intermediária de qualificação para o trabalho na realização de tais cursos. O parágrafo 11 do artigo 36, da Lei $\mathrm{n}^{\circ}$ 13.415/2017, ainda diz que, para garantir o cumprimento das exigências curriculares do ensino médio, os sistemas de ensino "poderão reconhecer competências e firmar convênios com instituições de educação a distância com notório reconhecimento" (BRASIL, 2017a).

Quantas escolas públicas brasileiras possuíam infraestrutura para ofertar diferentes itinerários formativos e tecnologia de ponta aos seus alunos há mais de 30 anos atrás e hoje em dia? Com certeza muitas delas se conveniaram a instituições privadas para dar conta do recado e estão fazendo isso atualmente, fenômeno causado de forma intencional. Dentro da lógica capitalista, se sucateia e se critica o público para que o privado seja visto como a solução, estabelecendo um cenário educacional lucrativo.

Por fim, a Lei $\mathrm{n}^{\circ}$ 5.692/71 afirmava que as habilitações profissionais podiam ser realizadas em regime de cooperação com as empresas, os conhecidos estágios, que não deveriam acarretar nenhum vínculo empregatício às empresas, mesmo que o estagiário fosse remunerado. Já a Lei $\mathrm{n}^{\circ}$ 13.415/2017 fala em inclusão de vivências práticas de trabalho no setor produtivo ou em ambientes de simulação, por meio de parcerias e do uso de instrumentos estabelecidos pela legislação sobre aprendizagem profissional.

Em seguida, buscar-se-á na história os motivos possíveis para tais proximidades entre as legislações vistas há pouco, distantes no tempo, mas tão próximas em suas concepções.

\section{A HISTÓRIA E OS POSSÍVEIS MOTIVOS DE TANTA SEMELHANÇA}

O processo de industrialização brasileiro começou ainda no século XIX, com a chegada da família real portuguesa ao Brasil, mas se intensificou no século XX, mais especificamente a partir da década de 1930 e durante toda a era Vargas. No período entre 1950 e 1980, o país passa pelo maior processo de modernização industrial de sua história, o qual altera profundamente suas configurações sociais, econômicas e políticas (SILVA, 1996).

Nessa direção, todos os setores da vida brasileira passaram por transformações rápidas e alterações estruturais importantes. De acordo com Silva (1996, p. 301), tais alterações "reafirmam 
estruturas já implantadas antes de 1950: a industrialização, a concentração de renda e a integração no conjunto econômico capitalista mundial".

A nível global, Couto (1999) aponta a década de 1960 como o auge da Guerra Fria, tempo de viva disputa indireta e estratégica entre duas grandes potências, Estados Unidos e União Soviética. O conflito pós-Segunda Guerra Mundial (1945) dividia o planeta em dois blocos geopolíticos - capitalistas versus socialistas - e transformava o mundo todo em palco da competição (COUTO, 1999, p. 23). Nessa mesma década, o Brasil vivia um momento de forte instabilidade política e econômica, que culminou no golpe militar de 1964. Esse acontecimento histórico significou o rompimento com o populismo e o aprofundamento das tendências econômicas preexistentes (MENDONÇA \& FONTES, 1991, p. 5).

O período de 1961 a 1964 foi marcado por um quadro político, econômico e social de exacerbação, afirmam Mendonça \& Fontes (1991, p. 7), no qual “as disputas partidárias, a polêmica entre Executivo e Legislativo, as greves, a inflação, as conspirações, revelam a estreita relação entre todos esses elementos e sua importância para o desfecho militar". Conforme as autoras, tratava-se realmente de um período descendente do ciclo econômico, mas não de uma crise econômica de proporções tão grandes que pusesse em risco a continuidade da acumulação capitalista. Para elas, o que realmente estava incomodando era a participação crescente das camadas trabalhadoras, que começaram a lutar e a disputar com os grupos dominantes quem teria maior peso político para conduzir o Estado na direção da satisfação de seus interesses.

Assim, nas palavras de Couto (1999, p. 24), o ano de 1964 começa ameaçador no Brasil: “a esquerda teme o golpe da direita, e a direita, autogolpe do presidente João Goulart”. A primeira hipótese se confirmou. João Goulart foi deposto por um golpe de estado no dia 31 de março e no dia $1^{\mathrm{o}}$ de abril foi instaurado o regime militar, com Castelo Branco no poder. Os conspiradores civis e militares, responsáveis pelo golpe, alegavam alguns objetivos principais: frustrar o plano comunista de conquista do poder e, com isso, restaurar a democracia e defender as instituições militares; e, restabelecer a ordem para acabar com a corrupção e promover o desenvolvimento (FAUSTO, 2006; VIANA FILHO, 1975).

Para Skidmore (1991, p. 22), a explicação mais imediata de como os inimigos do presidente brasileiro conseguiram expulsá-lo do governo e do país é a de que os civis que faziam oposição à João Goulart haviam conquistado a simpatia dos militares, "fator essencial para o bom êxito de um golpe". Contudo, o autor explica que não foi nem necessário o trabalho de persuasão dos militares para com os civis, pois em 1963 a maioria estava convencida de que "Goulart estava levando o 
Brasil para um estado socialista que extinguiria os valores e as instituições tradicionais do país". Provavelmente isso se deve ao fato de que o golpe foi apoiado pela maior parte da mídia brasileira (Jornal do Brasil, Correio da Manhã, O Globo, Folha de S. Paulo, O Estado de São Paulo, apoiavam abertamente a deposição do atual presidente) e pelo alto escalão da igreja (SKIDMORE, 1991).

Ainda conforme o autor, os conspiradores sustentavam ideias claramente anticomunistas desenvolvidas na Escola Superior de Guerra $(\mathrm{ESG})^{5}$ :

Da doutrina ali ensinada constava a teoria da 'guerra interna' introduzida pelos militares no Brasil por influência da revolução cubana. Segundo essa teoria, a principal ameaça vinha não da invasão externa, mas dos sindicatos trabalhistas de esquerda, dos intelectuais, das organizações de trabalhadores rurais, do clero e dos estudantes e professores universitários. Todas essas categorias representavam séria ameaça para o país e por isso teriam que ser todas elas neutralizadas ou extirpadas através de ações decisivas (SKIDMORE, 1991, p. 22).

A presença norte-americana no Brasil, contudo, vai muito além disso. Segundo Couto (1999, p. 24), o governo dos Estados Unidos acompanhava todos esses acontecimentos de perto, uma vez que viam uma "perigosa efervescência político-ideológica" no país, que podia conduzir a “instável democracia populista ao comunismo soviético". Por meio do acesso e da tradução de registros oficiais sobre a época, Couto (1999, p. 24) afirma que em 20 de dezembro de 1963, o presidente americano Lyndon Johnson disse ao senador Mike Mansfield que precisava conversar com ele sobre o que estava acontecendo no Brasil. Dizia ele, segundo o autor, que Washington não admitia outra Cuba, ainda mais de dimensões continentais e país mais populoso e economicamente mais importante da América do Sul.

Couto (1999) reproduz parte de um diálogo que Lyndon Johnson teve com o assessor George Reedy em 30 de março de 1964, às 21 h30 de Washington, o qual comprova que ele soube antecipadamente do golpe militar de 1964 no Brasil. Além disso, o autor mostra que os Estados Unidos pretendiam agir diretamente no confronto caso fosse preciso. "A operação Brother Sam, discretamente deflagrada nos Estados Unidos no final de março de 1964, consistia em apoio logístico ao golpe. Como não houve resistência, a Brother Sam foi suspensa" (COUTO, 1999, p. 25-26).

\footnotetext{
${ }^{5}$ A Escola Nacional de Guerra brasileira (ESG) seguia, conforme Skidmore (1991), o modelo do National War College dos Estados Unidos.
} 
Após o golpe, Lyndon Johnson enviou uma mensagem de congratulação a Ranieri Mazzilli6 horas depois de seu juramento como presidente em exercício por sugestão do embaixador Lincoln Gordon (Skidmore, 1991, p. 66). De acordo com Skidmore (1991, p. 66), Johnson dizia na mensagem que estava "satisfeito em saber que os brasileiros estavam resolvendo suas dificuldades "no contexto da democracia constitucional"' e previa a intensificação da cooperação norteamericana no interesse do progresso econômico e da justiça social para todos.

Instaurado então o regime militar, as mudanças começaram a ser colocadas em prática através de meios legais por meio dos chamados atos institucionais. A Constituição de 1946 e o funcionamento do Congresso foram mantidos, mas com várias modificações, como aponta Fausto (2006, p. 257). O período também foi marcado pela repressão severa de todos aqueles que se manifestavam de maneira contrária ao governo e líderes que estavam supostamente levando o Brasil para o comunismo foram perseguidos e presos na "Operação Limpeza", entre eles Paulo Freire (SKIDMORE, 1991).

Além disso, o regime militar se empenhou fortemente em desenvolver economicamente o Brasil com segurança. Conforme Saviani (2008a, p. 367), o lema positivista "Ordem e Progresso", inscrito na bandeira do Brasil, se transformou em "Segurança e Desenvolvimento". O autor destaca a adoção de um modelo econômico associado-dependente, consequência da presença das empresas internacionais no país e reforço dos laços do Brasil com os Estados Unidos. Esse contexto trouxe uma grande demanda social de preparo de mão de obra para esse mercado de trabalho, a qual exigiu a elevação geral da produtividade do sistema escolar.

A relação entre educação e desenvolvimento já estava presente nos debates educacionais, principalmente desde a metade dos anos 1950. A partir da década de 1960 e sobretudo na ditadura militar, essa associação e o conceito de educação como investimento ganharam ainda mais força e mais espaço. Nessa direção, Fávero (2005, p. 243, 244) explica que:

No mesmo movimento ideológico, também o conceito de educação como investimento, utilizado por vários congressistas nos debates do Congresso Constituinte, sobretudo para justificar a vinculação de recursos orçamentários para a educação, estava presente nos estudos que abordavam o ensino médio e superior e a

\footnotetext{
${ }^{6}$ Foi presidente do Brasil em dois momentos: após a renúncia de Jânio Quadros e durante a ausência do vicepresidente João Goulart, que estava em visita oficial à República Popular da China (de 25 de agosto a 7 de setembro de 1961) e logo após a deposição de João Goulart pelo Regime Militar (de 2 de abril de 1964 a 15 de abril de 1964) (SKIDMORE, 1991).
} 
capacitação de pessoal, desde meados da década de 1950. Nos anos de 1960, esse conceito e mais profundamente a relação educação e economia foram amplamente difundidos a partir da Reunião Extraordinária do Conselho Interamericano Econômico e Social, realizada em Punta del Este, em outubro de 1961, sob a coordenação da OEA e com a participação dos Ministros da Economia e das Finanças de todos os países da América Latina, da qual resultou o Plano Decenal de Educação da Aliança para o Progresso, e sobretudo, a Conferência sobre Educação e Desenvolvimento Econômico e Social na América Latina, promovida pela OEA, Cepal, Unesco e FAO, com a participação de todos os ministros de Educação latino-americanos, em Santiago do Chile, março de 1962.

Nesse contexto, o autor afirma que a concepção de educação como "preparadora de recursos humanos para as tarefas da industrialização, modernização da agropecuária e ampliação dos serviços" tornou-se fortemente hegemônica, fundamentada principalmente na teoria do capital humano e traduzida no enfoque da mão-de-obra. Nessa perspectiva, o sistema educacional como um todo devia estar voltado para a formação do homem brasileiro, considerando as atividades do crescimento econômico.

O acelerado ritmo de crescimento da demanda social por educação, de acordo com Romanelli (1978, p. 196), provocou o agravamento da crise do sistema educacional que já vinha de anos anteriores. Na realidade, segundo a autora, esse fato serviu de justificativa para que o Brasil assinasse uma série de convênios entre o MEC, seus órgãos e a Agency for International Development (AID). A partir disso, essa Agência passou a prestar assistência técnica e cooperação financeira à educação brasileira e a interferir na organização do sistema educacional do país.

A interferência direta de órgãos internacionais na educação brasileira legitimou aquilo que Saviani (2008a, p. 297) chamou de "concepção produtivista de educação". Segundo ele, um ensino baseado nos princípios da racionalidade, eficiência e produtividade, e nas premissas do "máximo resultado com o mínimo dispêndio" e "não duplicação de meios para fins idênticos". É justamente esse modelo que ganhou força ao ser incorporado à legislação do ensino no período militar, conclui o autor.

De fato, Romanelli (1978, p. 197) esclarece que os chamados "acordos MEC-USAID" forneceram as bases principais das reformas educacionais realizadas na época, especialmente por meio comissão Meira Matos. Conforme ela, cabia à comissão intervir nos focos de agitação estudantil (as escolas superiores foram tomadas em junho de 1968 pelos estudantes como forma de protesto frente à crise educacional e à repressão do governo ditatorial) e estudar a crise em si para 
propor medidas de reforma. O relatório apresentado pela Meira Matos nada mais fez do que reforçar as propostas surgidas com os acordos internacionais, destaca a autora.

Outros documentos que influenciaram as políticas educacionais desse momento histórico, tanto quanto o Relatório Meira Matos, foram os elaborados pelo Grupo de Trabalho da Reforma Universitária. Além do desenvolvimento de um relatório contendo sugestões de medidas a serem adotadas na educação superior, o GT formulou e apresentou o anteprojeto que virou a Lei $\mathrm{n}^{\circ}$ 5.540/68 (ROMANELLI, 1978, p. 197).

Buscando atingir seus objetivos sociais, políticos e econômicos, o regime militar implementou duas reformas jurídicas no campo da educação: a Lei n ${ }^{\circ} 5.540$, de 28 de novembro de 1968, que reorganizou o funcionamento do ensino superior e sua articulação com a escola média; e a Lei $\mathrm{n}^{\mathrm{o}} 5.692$, de 11 de agosto de 1971, que reestruturou os antigos primário e ginásio criando o ensino de $1^{\circ}$ e $2^{\circ}$ graus (SAVIANI, 1987, p. 99). Assim, os quatro anos do ensino primário e os quatro anos do ginásio foram unificados em um ciclo de oito anos, nomeado $1^{\circ}$ grau e de caráter obrigatório, e o ensino colegial se transformou em $2^{\circ}$ grau, com três ou quatro anos de duração.

Fávero (2005, p. 245) é enfático ao dizer que essas reformas foram cruciais ao movimento de subordinar a educação, em todos os seus níveis e modalidades, "ao projeto autoritário de crescimento econômico e inserção subordinada da economia brasileira no capitalismo internacional". De acordo com o autor, essa concepção aparece claramente no Programa Estratégico de Desenvolvimento elaborado em 1967, que propõe a "reformulação do ensino médio, para constituir, com o primário, [...] um sistema fundamental que assegure a formação básica do educando e sua preparação para as atividades econômicas na indústria, agricultura e serviços" (BRASÍLIA, 1967, p. 99).

As alterações realizadas na legislação impactaram significativamente a prática educacional no país e configuraram uma nova categoria docente. Isso porque a ampliação da escolaridade obrigatória de quatro para oito anos provocou um rápido aumento no número de escolas de ensino fundamental e exigiu a pronta formação de professores para atender essas demandas, explicam Ferreira Júnior e Bittar (2006, p. 69). Os autores afirmam que "a combinação entre crescimento quantitativo, formação acelerada e arrocho salarial deteriorou ainda mais as condições de vida e de trabalho do professorado nacional de ensino básico” (p. 70).

A propósito desse tema, Saviani (2008b, p. 298) discorre longamente sobre o favorecimento da iniciativa privada por parte do governo militar. O autor sustenta essa afirmação através da legislação do período, apontando que a Constituição de 24 de janeiro de 1967 descontinuou a 
vinculação orçamentária que obrigava a União, os estados e os municípios a destinar um percentual mínimo de recursos para a educação prevista nas Constituições de 1934 e 1946. O mesmo documento previu ainda apoio à iniciativa privada, afirmando no $\S 2^{\circ}$ do artigo 168 que o ensino era livre à iniciativa particular, que merecia o amparo técnico e financeiro dos Poderes Públicos, inclusive bolsas de estudo (SAVIANI, 2008b, p. 299).

Além disso, Saviani (2008b) destaca ainda que a Constituição de 1967 relativizou o princípio da gratuidade do ensino, direito garantido por todas as Constituições desde 1824, quando Dom Pedro I outorgou a primeira Carta Magna do Brasil. Dessa forma, o governo federal foi reduzindo gradativamente os recursos destinados à educação. Seguindo essa lógica, o Grupo de Trabalho da Reforma Universitária instituído naquela época recomendou, segundo o autor, que a partir de 1969 os novos universitários passassem a pagar pelos estudos nas universidades públicas de acordo com sua renda. Essa sugestão não foi adotada, mas sim outras estratégias de privatização do ensino que alavancaram o aumento de instituições privadas de ensino, principalmente de nível superior, como mostra Saviani (2008b, p. 112).

De fato, ocorreu no período uma grande expansão do ensino superior. Entre 1964 e 1973, enquanto o ensino primário cresceu 70,3\%; o ginasial, 332\%; o colegial, 391\%; o ensino superior foi muito além, tendo crescido no mesmo período 744,7\%.1 E o grande peso nessa expansão se deveu à iniciativa privada: entre 1968 e 1976, o número de instituições públicas de ensino superior passou de 129 para 222, enquanto as instituições privadas saltaram de 243 para 663.

Resumindo, as políticas educacionais adotadas ao longo do regime militar provocaram mudanças que, em linhas gerais, assumiram um viés tecnicista, provocaram uma expansão quantitativa da escola pública de $1^{\circ}$ e $2^{\circ}$ que custou a queda da sua qualidade; instauraram o cerceamento e controle das atividades acadêmicas no interior das universidades; e, proporcionaram a expansão da iniciativa privada no ensino superior. Algumas dessas medidas ainda estão visivelmente presentes no cenário atual.

A década de 1980 foi marcada pelo retorno gradual dos debates, o ímpeto de uma avassaladora insatisfação popular sem esperanças, o retorno do pensamento crítico de esquerda, os efeitos internos das perturbações estruturais do capitalismo mundial, a crise do "milagre" e a depressão da economia brasileira expõem as fraturas da base econômica, social e política da ditadura militar e apontam para o desgaste político do regime (FERNANDES, 1982, p. 7). No 
campo teórico e epistemológico, segundo Frigotto (2015, p. 209), “vivia-se um contexto no Brasil de expansão da pós-graduação nas ciências sociais e humanas e a incorporação, em alguns programas de pós-graduação em educação, da leitura de obras de Marx e outros autores da tradição marxista".

Como visto anteriormente, particularmente na esfera educacional, a ditadura-civil militar efetivou reformas em todos os níveis de ensino com base na concepção de capital humano formulada ao longo da segunda metade do século XX por Theodore Schultz (1973). De acordo com Frigotto (1995), a noção de capital humano é formulada a partir de dois fenômenos que figuravam naquele momento: a crise das políticas keynesianas e da do Estado de Bem-Estar Social no combate à desigualdade entre nações, classes e grupos sociais; e, pela maneira invertida dos intelectuais burgueses compreenderem a natureza implícita e estrutural da crise do capital e as políticas de enfrentamento dessa crise.

Nesse contexto, Schultz (1973) observou que as famílias que investiam mais em educação formal e em saúde tinham retornos maiores do que as demais. Após comparar o Produto Interno Bruto (PIB) e a escolaridade, encontrou uma correlação estreita entre ambas. Esse experimento foi a base do desenvolvimento daquilo que ele chamou de teoria do capital humano, na qual afirma que "todo indivíduo é capitalista pela aquisição de conhecimentos e de capacidades que possuem valor econômico" (SCHULTZ, 1973, p. 7).

Porém, tal teoria não levou em conta as desigualdades históricas entre classes e nações, aponta Frigotto (2015). Para o autor, Schultz é a representação dos intelectuais burgueses que, por sua condição de classe, "buscam explicar a sociedade e suas relações sociais pelo Estado, pelo sistema jurídico, pela educação, pela saúde etc. e não entendem que o Estado, o sistema jurídico e político, a educação, a saúde etc. são produtos das relações entre as classes sociais e que buscam, dialeticamente, reproduzir a ordem social da qual emergem" (p. 217).

Nessa direção, Arapiraca (1979, p. 33) aponta alguns pontos centrais dessa teoria. O capital humano é produzido pelo investimento na educação formal e no treinamento dos indivíduos. Este duplo investimento faz com que a produtividade da pessoa aumente, assim como a sua renda. Portanto, a principal função da educação nessa concepção é “desenvolver as habilidades e conhecimentos objetivando o aumento da produtividade; um maior índice de estudos corresponde a um maior número de ganhos de habilidades cognitivas; e finalmente, quanto maior for o grau de produtividade, maior será a cota de renda que a pessoa perceberá” (ARAPIRACA, 1979, p. 34). 
Frigotto (2015, p. 217) enfatiza que essa noção de capital humano reduz a concepção de ser humano a uma mercadoria, seja de trabalho (ao confundir a atividade vital que produz e reproduz o ser humano e que é pressuposto das demais atividades humanas, à venda da força de trabalho humana); de sociedade (ao tomá-la como um contínuo dos mais pobres aos mais ricos, ignorando a estrutura desigual e antagônica das classes sociais); e, de classe social (tomando-a por fatores isolados e independentes na compreensão da sociedade e, finalmente, de educação, de um direto social e subjetivo a uma concepção mercantil de formação humana).

Contudo, essa noção de capital humano que orientou as reformas educacionais no período da ditadura civil-militar não é mais o mesmo. Ele mudou na mesma medida que as configurações sociais mudaram, ressignificando rapidamente as relações sociais, políticas e econômicas. Ao longo dos pouco mais de 30 anos que se passaram desde o fim do governo militar, Frigotto (2015) afirma que as relações sociais capitalistas estão assumindo um caráter cada vez mais opaco, violento e regressivo diante do aprofundamento e das particularidades da crise do capital.

Compartilhando do ponto de vista de Altvater (2010), a atual crise do capital é universal, global e cada vez mais irreversível, diferente das anteriores, produzidas pelo próprio caráter contraditório do modo de produção capitalista. As duas últimas décadas do século XX foram palco de uma verdadeira revolução tecnológica que inaugurou a era da informação e de grandes movimentos sociais como os do leste europeu, que culminaram na queda do Muro de Berlim (GADOTTI, 2000, p. 3).

Esse salto tecnológico alterou substancialmente as formas de produção, afirma Frigotto (2015). O autor chama a atenção para o movimento de apropriação das inovações tecnológicas por parte da iniciativa privada e o monopólio dessas tecnologias por megagrupos detentores do capital. Para Frigotto (2015, p. 218), esse fenômeno ampliou a desigualdade entre as nações e permitiu a supremacia do capital sobre as conquistas e direitos da classe trabalhadora, levando ao colapso do socialismo real. Tal colapso permitiu, segundo ele, que as forças do capital decretassem o retorno da tese ultraconservadora de que:

[...] o capitalismo se constitui numa sociedade de tipo natural, por supostamente corresponder ao que é a natureza humana: a busca do bem individual próprio, o egoísmo produtivo" (p. 216). Doutrina esta que, no plano do pensamento crítico, paradoxalmente, assumiu o termo de neoliberalismo. Talvez, a denominação mais adequada fosse a de neoconservadorismo (Frigotto, 2015, p. 216). 
Uma das consequências dessas transformações é o surgimento de novas noções ideológicas, especialmente de capital humano, "que buscam mascarar o que está subjacente à crise do capital e suas consequências funestas para a vida da maioria dos seres humanos” (Frigotto, 2015, p. 216).

As novas tecnologias possibilitaram a substituição do homem pela máquina em grandes proporções, fazendo com que enormes contingentes de trabalhadores fossem demitidos. Assim, conferiram grande poder e mobilidade ao capital produtivo e financeiro, que buscam continuamente eliminar ou flexibilizar as leis que protegem os empregados e instaurar processos de superexploração. Como o capital já não precisa mais de tanta força de trabalho, resta espaço apenas para os mais “competentes" (Santos \& Mesquida, 2014), aqueles que desenvolveram as qualidades técnicas e psicossociais que interessam ao mercado por seu esforço individual e mérito próprio.

Sendo assim, na atual relação entre capital e trabalho a qualidade já não basta, é preciso atingir a qualidade total. Essa noção exige, portanto, que o trabalhador produza uma mercadoria ou serviço com a máxima qualidade com o menor tempo e o menor custo possíveis. De noções mais gerais como essa derivam outras que, segundo Frigotto (2015, p. 220), "foram aparecendo no vocabulário social e educacional e que incidem política e ideologicamente na hipertrofia do individualismo".

O regresso das políticas sociais e a consequente degradação da vida da classe trabalhadora provocadas pela crise do capital têm sua raiz no ideário do capital humano, afirma Frigotto (1995). Incorporam e aprofundam, segundo o autor, seu caráter invertido de compreender a realidade, ou seja, a crença no pleno emprego e na integração (mesmo que desigual) de toda força de trabalho. Crença porque, como bem explica Frigotto (1995), o capitalismo pressupõe um exército de reserva.

No campo da educação, "trata-se de educar para a empregabilidade e esta depende de cada um" (FRIGOTTO, 2015, p. 221). O autor destaca que o termo "qualificação", ligado a emprego e ao um conjunto de direitos dos trabalhadores que contavam com sindicatos fortes, passa a ser substituído por "competências" no vocabulário social e pedagógico. Essas competências são as exigidas pelo mercado de trabalho, o que faz com que o setor produtivo privado (nacional e internacional) seja o principal orientador dos currículos e dos conteúdos, dos métodos de ensino e de avaliação, das políticas públicas educacionais.

Apesar das mudanças sociais provocadas pela revolução tecnológica e pela crise do capital, uma série de raízes históricas se aprofundaram diante de pouca ou nenhuma alteração. A sociedade brasileira continua a ser uma sociedade de capitalismo dependente, como a define Fernandes (1975), com uma classe média que defende apenas seus interesses próprios, associada ao grande 
capital. Disto resulta uma sociedade na qual o aumento da riqueza de poucos mantém e amplia a pobreza da maioria.

\section{CONCLUSÃO}

Diferentes pesquisadores, como vimos, são enfáticos ao dizer que a Ditadura Civil-Militar brasileira deixou marcas permanentes. Ela encontrou uma maneira pérfida de permanecer em nossa estrutura jurídica, nossas práticas políticas, na violência cotidiana e em nossos traumas sociais, declara Benjamin (2010, p. 4). Teles e Safatle (2010, p. 10) salientam que há, de fato, uma "exceção brasileira", mas ela não está lá onde alguns gostariam que estivesse. Os autores afirmam com toda segurança que "a ditadura brasileira foi a ditadura mais violenta que o ciclo negro latino-americano conheceu", não pela quantidade de mortos que deixou para trás, mas pelo legado que deixou ao presente. Aí está a “exceção”.

Ao mesmo tempo que as pessoas negam o alcance da ditadura e minimizam sua herança autoritária no Brasil, a exceção brasileira indica as circunstâncias que permitiram certa continuidade da ditadura brasileira, reitera Benjamin (2010, p. 4). Para ele, a ditadura não está somente no lugar que a memória coletiva parece tê-la colocado e sua permanência não é mais a simples presentificação do que já foi, mas reaparece nas práticas institucionais de hoje. Como bem colocam Teles e Safatle (2010, p. 11), "isto não significa em absoluto cometer o erro primário de confundir nossa semidemocracia com uma ditadura, mas trata-se de lembrar de onde vem o que impede nossa experiência democrática avançar”.

O cenário que temos até hoje desde o fim da Ditadura Civil-Militar brasileira ainda é este:

Quando estudos demonstram que, ao contrário do que aconteceu em outros países da América Latina, as práticas de tortura em prisões brasileiras aumentaram em relação aos casos de tortura na ditadura militar; quando vemos o Brasil como o único país sul-americano onde torturadores nunca foram julgados, onde não houve justiça de transição, onde o Exército não fez um mea culpa de seus pendores golpistas; quando ouvimos sistematicamente oficiais na ativa e na reserva fazerem elogios inacreditáveis à ditadura militar; quando lembramos que 25 anos depois do fim da ditadura convivemos com o ocultamento de cadáveres daqueles que morreram nas mãos das Forças Armadas; então começamos a ver, de maneira um pouco mais clara, o que significa exatamente "violência". Pois nenhuma palavra melhor do que "violência" 
descreve esta maneira que tem o passado ditatorial de permanecer como um fantasma a assombrar e contaminar o presente (TELES \& SAFATLE, 2010, p. 10)

Consequentemente, a persistência do legado educacional da Ditadura Civil-Militar é totalmente compreensível, tendo em vista os problemas e ambiguidades da transição democrática em nosso país (SAVIANI, 2008b, p. 310). Na visão do autor, a transição democrática foi feita com base em uma conciliação superficial, que buscou garantir a continuidade da ordem socioeconômica. Essa continuidade foi reforçada a partir da década de 90, segundo ele, por uma nova onda conservadora de proporção mundial e pela primazia do mercado sob o comando do grande capital financeiro.

Nessa direção, Saviani (2008b, p. 291) destaca as principais heranças que o período ditatorial deixou para a educação:

[...] vinculação da educação pública aos interesses e necessidades do mercado, que se efetivou na reforma universitária e especialmente no intento de implantação universal e compulsória do ensino profissionalizante; favorecimento à privatização do ensino, que ocorreu principalmente mediante as autorizações e reconhecimentos do Conselho Federal de Educação; estrutura de ensino decorrente da implantação de mecanismos organizacionais que se encontram em plena vigência; um modelo bem sucedido de pós-graduação implantado a partir da estrutura organizacional americana e da experiência universitária europeia.

Essa conjuntura política, social e econômica foi extremamente propícia para a permanência e fortalecimento da teoria do capital humano e sua concepção de ser humano, sociedade, ciência, trabalho e educação. Frigotto $(2015$, p. 224) enfatiza que ela "não só permaneceu válida como ganhou mais densidade ao longo dos últimos trinta anos". O que especificamente se adensou ao longo dessas três décadas, conforme o autor, foi a noção de que os processos de conhecimento nas sociedades divididas em classes sociais não são neutros e são um componente da luta de classe. Por isso, Frigotto (2015, p. 227) esclarece que, mais grave do que a expansão do mercado privado na educação, é o direcionamento que essa concepção mercantil dá aos conteúdos, métodos e formas da educação pública. Para ele, essa realidade nos apresente um duplo e duro desafio:

No campo teórico desafia-nos o esforço de apreender, para além da aparência, o sentido do movimento da realidade. No plano político é urgente a construção de uma 
agenda que possa não apenas barrar a mercantilização, mas retomar o espaço da esfera pública. Único espaço, mesmo que restrito, de garantia de direitos universais (FRIGOTTO, 2015, p. 227).

Diante disso, fica mais claro o porquê as leis educacionais do período da ditadura militar se assemelham tanto com as de agora. O governo atual simpatiza com a ditadura militar e muitas de suas ideologias são uma espécie de retomada daquilo que vivemos entre as décadas de 60 e 80 . Os tempos são outros, muitas coisas mudaram, mas muitas raízes se aprofundaram e ganharam força, como visto anteriormente. Assim sendo, elas voltam à tona em governos socialmente conservadores, mas com condutas econômicas fortemente neoliberais ${ }^{7}$.

Isso faz com que valores conservadores adormecidos voltem com vigor no seio da sociedade, assim como a lógica mais capitalista possível. Nesse contexto, assim como ao longo de toda a história, a educação configura como um campo extremamente estratégico e é moldada para o alcance dos objetivos traçados. Trata-se de uma educação voltada para o mercado de trabalho; calcada em valores como o individualismo, a competitividade, o mérito próprio, o desenvolvimento das competências exigidas pelo mundo capitalista; uma educação que prioriza o conhecimento técnico e deixa de lado o pensamento crítico; que predestina a classe baixa para os níveis de emprego mais baixos e as classes altas para cargos mais altos.

Altvater (2010) é taxativo ao dizer que estamos longe de encontrar no mercado efeitos sociais e ambientais tão simples que possam ser corrigidos, ajustados ou compensados por políticas públicas ou taxações ecológicas. Ele alerta que a permanência da economia de mercado coloca a própria humanidade em risco e trará catástrofes sociais e ecológicas, desemprego em massa, terrorismo e guerras de espoliação (fenômenos que já estão acontecendo e se intensificando, por sinal). Trata-se da insustentabilidade do capitalismo, que o levará ao seu fim tal como o conhecemos. Que nessa onda de transformações, a educação também possa se reinventar e servir a propósitos mais humanos, mesmo que isso seja a longo prazo.

\footnotetext{
${ }^{7}$ Minha opinião é que [o neoliberalismo] se refere a um projeto de classe que surgiu na crise dos anos 1970. Mascarada por muita retórica sobre liberdade individual, autonomia, responsabilidade pessoal e as virtudes da privatização, livre-mercado e livre-comércio, legitimou políticas draconianas destinadas a restaurar e consolidar o poder da classe capitalista. Esse projeto tem sido bem-sucedido, a julgar pela incrível centralização da riqueza e do poder observável em todos os países que tomaram o caminho neoliberal. E não há nenhuma evidência de que ele está morto (HARVEY, 2011, p. 16).
} 


\section{REFERÊNCIAS}

ALTVATER, Elmar. O fim do capitalismo como o conhecemos. Rio de Janeiro: Civilização Brasileira, 2010.

ARAPIRACA, José Oliveira. A USAID e a educação brasileira: um estudo a partir de uma abordagem crítica do capital humano. Rio de Janeiro, 1979.

BENJAMIN, Walter. Sobre o que resta da ditadura. In: O que resta da ditadura: a exceção brasileira. Edson Teles e Vladimir Safatle (Orgs.). São Paulo: Boitempo, 2010.

BRASIL. Constituição da República Federativa do Brasil, 1988. Acesso em: janeiro, 2019. Disponível em: http://www.planalto.gov.br/ccivil_03/Constituicao/Constituicao.htm.

BRASIL. Lei $n^{\circ}$ 5.540, de 28 de novembro, 1968. Fixa normas de organização e funcionamento do ensino superior com a escola média e dá outras providências. Acesso em: janeiro, 2019. Disponível em: http://www.planalto.gov.br/ccivil_03/LEIS/L5540.htm.

BRASIL. Lei $\mathrm{n}^{\circ}$ 5.692, de 11 de agosto, 1971. Fixa Diretrizes e Bases para o ensino de $1^{\circ}$ e $2^{\circ}$ graus, e dá outras providências. Acesso em: janeiro, 2019. Disponível em: http://www2.camara.leg.br/legin/fed/lei/1970-1979/lei-569211-agosto-1971-357752-publicacaooriginal-1-pl.html.

BRASIL. Lei de Diretrizes e Bases da Educação Nacional n 9.394, de 20 de dezembro, 1996. Estabelece as diretrizes e bases da educação nacional. Acesso em: janeiro, $2019 . \quad$ Disponível em: http://www.planalto.gov.br/ccivil_03/LEIS/L9394.htm.

BRASIL. Projeto de Lei $n^{\circ}$ 6.840, 2013a. Formulado pela Comissão Especial destinada a promover Estudos e Proposições para a Reformulação do Ensino Médio - CEENSI. Acesso em: janeiro, 2019. Disponível em: http://www.camara.gov.br/proposicoesWeb/fichadetramitacao?idProposicao=602570.

BRASIL. Ministério da Educação - MEC. Diretrizes Curriculares Nacionais da Educação Básica, 2013b. Acesso em: janeiro, 2019. Disponível em: http://portal.mec.gov.br/docman/julho-2013-pdf/13677-diretrizes-educacao-basica-2013pdf/file.

BRASIL. Lei $n^{\circ} 12.796$, de 4 de abril, 2013c. Altera a Lei $n^{\circ}$ 9.394, de 20 de dezembro de 1996, que estabelece as diretrizes e bases da educação nacional, para dispor sobre a formação dos profissionais da educação e dar outras providências. Acesso em: janeiro, 2019. Disponível em: http://www.planalto.gov.br/ccivil_03/_Ato20112014/2013/Lei/L12796.htm.

BRASIL. Lei n ${ }^{13.005}$, de 25 de junho, 2014. Aprova o Plano Nacional de Educação - PNE e dá outras providências. Acesso em: janeiro, 2019. Disponível em: http://www2.camara.leg.br/legin/fed/lei/2014/lei-13005-25-junho-2014778970-publicacaooriginal-144468-pl.html.

BRASIL. Medida Provisória no 746, 2016a. Reformulação Ensino Médio. Acesso em: janeiro, 2019. Disponível em: https://www.congressonacional.leg.br/materias/medidas-provisorias/-/mpv/126992.

BRASIL. Medida Provisória no 241, 2016b. Altera o Ato das Disposições Constitucionais Transitórias, para instituir o Novo Regime Fiscal. Acesso em: janeiro, 2019. Disponível em: https://www.camara.gov.br/proposicoesWeb/fichadetramitacao?idProposicao=2088351\#marcacao-conteudo-portal.

BRASIL. Lei ${ }^{\circ}$ 13.415, de 16 de fevereiro, 2017a. Conversão da Medida Provisória n ${ }^{\circ}$ 746, de 2016. Acesso em: janeiro, 2019. Disponível em: https://www2.camara.leg.br/legin/fed/lei/2017/lei-13415-16-fevereiro-2017-784336publicacaooriginal-152003-pl.html.

BRASIL. Ministério da Educação - MEC. Base Nacional Comum Curricular, 2017b. Acesso em: janeiro, 2019. Disponível em: http://portal.mec.gov.br/conselho-nacional-de-educacao/base-nacional-comum-curricular-bncc.

BRASIL. Ministério da Educação - MEC. Versão completa em revisão do documento referente às alterações na etapa do Ensino Médio, aprovada pelo CNE em 04 de dezembro, 2018. Acesso em: janeiro, 2019. Disponível em: http://basenacionalcomum.mec.gov.br/wp-content/uploads/2018/12/BNCC-

EM_Vers\%C3\%A3oCompleta_EmRevis\%C3\%A3o_06dez.pdf

COUTO, Ronaldo Costa. História indiscreta da ditadura e da abertura: Brasil: 1964-1985. 2a ed. Rio de Janeiro: Record, 1999. 
BRASÍlIA. DIRETRIZES DE GOVERNO. Programa Estratégico de Desenvolvimento, Brasília, Ministério do Planejamento e Coordenação Geral, 1967, p. 99.

GADOTTI, Moacir. Perspectivas atuais da educação. São Paulo em perspectiva, 2000.

GONTIJO; Cláudia Maria Mendes. O Ensino de Língua Portuguesa e a Base Nacional Comum Curricular. Revista Brasileira de Alfabetização, ABAlf. Vitória, ES.v.1, n.2, p. 174-190, 2015.

HARVEY, David. O enigma do capital: e as crises do capitalismo. Tradução: João Alexandre Peschanski. São Paulo, SP : Boitempo, 2011.

KRAWCZYK, Nora. Reflexão sobre alguns desafios do ensino médio no Brasil hoje. Cadernos de Pesquisa, v. 41, n.144. set./dez.. São Paulo, 2011.

MENDONÇA, Sônia Regina de; FONTES, Virgínia Maria. História do Brasil recente: 1964-1980. 2a ed. São Paulo: Ática, 1991 .

SANTOS, M. S. E MESQUIDA, P. As matilhas de Hobbes: o modelo da pedagogia por competência. São Paulo: Associação Brasileira de Editoras Universitárias, 2014.

FAUSTO, Boris. História concisa do Brasil. 2a ed. São Paulo: Editora da Universidade de São Paulo, 2006.

FÁVERO, Osmar (Org.). A educação nas constituintes brasileiras 1823-1988. $3^{\mathrm{a}}$ ed. Campinas, SP: Autores Associados, 2005.

FERNANDES, Florestan. A ditadura em questão. São Paulo: T. A. Queiroz, 1982.

. Capitalismo dependente e classes sociais na América Latina. 2. ed. Rio de Janeiro: Zahar,

1975.

FERREIRA JÚNIOR, Amarilio; BITTAR, Marisa. Proletarização e sindicalismo de professores na ditadura militar (1964-1985). São Paulo: Terras do Sonhar: Edições Pulsar, 2006.

FRIGOTTO, Gaudêncio. Educação e crise do capitalismo real. $1^{\text {a }}$ ed. São Paulo: Cortez, 1995.

. A produtividade da escola improdutiva 30 anos depois: regressão social e hegemonia às avessas. Ano 13, nº 20, TrabalhoNecessário, 2015.

ROMANELLI, Otaíza de Oliveira. História da educação no Brasil (1930/1973). Petrópolis, RJ: Editora Vozes, 1978.

SAVIANI, Dermeval. História das ideias pedagógicas no Brasil. $2^{\text {a }}$ ed. revisada e ampliada. Campinas, SP: Autores Associados, 2008a.

set./dez. $2008 b$.

O legado educacional do regime militar. Cad. Cedes, Campinas, vol. 28, n. 76, p. 291-312,

Política e educação no Brasil: o papel do Congresso Nacional na legislação do ensino. São Paulo: Cortez \& Autores Associados, 1987.

SCHULTZ, Temore W. O Capital Humano. Zahar Editores, Rio de Janeiro, 1973.

SKIDMORE, Thomas E. Brasil: de Castelo a Tancredo, 1964-1985. Tradução de Mario Salviano Silva. $4^{\mathrm{a}}$ ed. Rio de Janeiro: Paz e Terra, 1991.

SILVA, Francisco Carlos Teixeira da. A modernização autoritária: do golpe militar à redemocratização 1964-1984. In: História geral do Brasil. Maria Yeda Linhares (organizadora). 6ª ed. Rio de Janeiro: Campus, 1996.

TELES, Edson; SAFATLE, Vladimir. O que resta da ditadura: a exceção brasileira. São Paulo: Boitempo, 2010.

TRICHES, Eliane de Fátima; ARANDA, Maria Alice de Miranda. A formulação da base nacional comum curricular (BNCC) como ação da política educacional: breve levantamento bibliográfico (2014-2016). Revista Realização, volume $3, \mathrm{n}^{\circ} 5,2016$.

VIANA FILHO, Luís A. O governo Castelo Branco. Rio de Janeiro: José Olímpio, 1975.

\section{RESUMO}

Mais de três décadas depois, uma Reforma do Ensino Médio e uma Base Nacional Comum Curricular (BNCC) aprovadas entre 2017 e 2018 apresentam grande semelhança com a Reforma do Ensino de $1^{\circ}$ e $2^{\circ}$ graus da época da Ditadura Civil-Militar no Brasil. No que as Leis no 12.796/2013, no 13.415/2017 e a no 5.692/71 se assemelham? Quais seriam os possíveis motivos para essa proximidade? Este artigo busca responder essas questões, com o objetivo de compreender melhor porque o atual programa educacional é tão próximo do plano traçado para a educação no período ditatorial. Para isso, foi traçada uma analogia entre as leis 
supracitadas e foi lançado um breve olhar sobre a história, buscando nela razões plausíveis para este fato. Esta pesquisa bibliográfica teve como referência não somente a legislação pertinente, como também obras de autores como Altvater (2010); Arapiraca (1979); Benjamin (2010); Harvey (2011); Fausto (2006); Fernandes (1982); Frigotto (1995); Romanelli (1978); Saviani (2008); Schultz (1973); Skidmore(1991); Safatle \& Telles(2010). Concluiu-se que a Ditadura Civil-Militar brasileira deixou marcas permanentes ao presente, que permeiam insidiosamente nossas estruturas econômicas, políticas e sociais. Aí está a grande importância de olhar cuidadosamente para esse fenômeno e compreender porque o programa educacional de hoje propõe uma espécie de retrocesso, entendido aqui como prejudicial à sociedade.

Palavras-chave: Reforma do Ensino Médio; Base Nacional Comum Curricular, BNCC, Ditadura Civil-Militar Brasileira.

\section{ABSTRACT}

More than three decades later, a High School Reform and a National Curricular Common Base (BNCC), approved between 2017 and 2018, are very similars to the Educational Reform of the 1st and 2nd grades made during the Brazilian Civil-Military Dictatorship. What do the Laws no 12.796/2013, no. 13.415/2017 and no 5.692/71 look like? What are the possible reasons for this proximity? This article seeks to answer these questions in order to better understand why the current educational program is so close to the plan drawn up for education in the dictatorial period. To this end, an analogy was drawn between the above-mentioned laws and a brief glance was taken on history, seeking in it plausible reasons for this fact. This bibliographic research had as reference not only the relevant legislation, but also works by authors such as Altvater (2010); Arapiraca (1979); Benjamin (2010); Harvey (2011); Fausto (2006); Fernandes (1982); Frigotto (1995); Romanelli (1978); Saviani (2008); Schultz (1973); Skidmore (1991); Safatle \& Telles (2010). It was concluded that the Brazilian Civil-Military Dictatorship left permanent marks to the present, insidiously permeating our economic, political and social structures. Here is the great importance of looking carefully at this phenomenon and understanding why the educational program of today proposes a kind of regression, understood here as harmful to society.

Key-words: High School Reform; National Curricular Common Base (BNCC), Brazilian Civil-Military Dictatorship.

\section{RESUMEN}

Más de tres décadas después, una Reforma de la Enseñanza Media y una Base Nacional Común Curricular (BNCC), aprobadas entre 2017 y 2018, presentan gran semejanza con la Reforma de la Enseñanza de $1^{\circ}$ y $2^{\circ}$ grados de la época de la Dictadura Civil-Militar en Brasil. En qué las Leyes no 12.796/2013, no 13.415/2017 y la no 5.692/71, se asemejan? ¿Cuáles serían los posibles motivos para esa proximidad? Este artículo busca responder a esas cuestiones, con el objetivo de comprender mejor porque el actual programa educativo es tan cercano al plan trazado para la educación en el período dictatorial. Para ello, se trazó una analogía entre las leyes arriba citadas y se lanzó una breve mirada sobre la historia, buscando en ella razones plausibles para este hecho. Esta investigación bibliográfica tuvo como referencia no sólo la legislación pertinente, como también obras de autores como Altvater (2010); Arapiraca (1979); Benjamin (2010); Harvey (2011); Fausto (2006); Fernandes (1982); Frigotto (1995); Romanelli (1978); Saviani (2008); Schultz (1973); Skidmore (1991); Safatle \& Telles (2010). Se concluyó que la Dictadura Civil-Militar brasileña dejó marcas permanentes al presente, que permean insidiosamente nuestras estructuras económicas, políticas y sociales. La gran importancia de mirar cuidadosamente hacia ese fenómeno y comprender por qué el programa educativo de hoy propone una especie de retroceso, entendido aquí como perjudicial para la sociedad.

Palabras clave: Reforma de la Enseñanza Media; Base Nacional Común Curricular (BNCC), Dictadura CivilMilitar Brasileña. 